1

2

3

4

5

6

7

8

9

10

11

12 Maosheng Yao, $\mathrm{PhD}$

13 Boya Distinguished Professor

14 State Key Joint Laboratory of Environmental Simulation and Pollution Control,

15 College of Environmental Sciences and Engineering, Peking University, Beijing

16 100871, China

17 Email: yao@pku.edu.cn, Ph: +86 01062767282

18 \# Both authors contributed equally

19

20

21

22

\section{Rats Sniff off Toxic Air}

\author{
Haoxuan Chen ${ }^{\#}$, Xinyue $\mathrm{Li}^{\#}$ and Maosheng Yao*
}


bioRxiv preprint doi: https://doi.org/10.1101/739003; this version posted February 1, 2020. The copyright holder for this preprint (which was not certified by peer review) is the author/funder, who has granted bioRxiv a license to display the preprint in perpetuity. It is made available under aCC-BY-NC 4.0 International license.

25

26

27

28

29

30

31

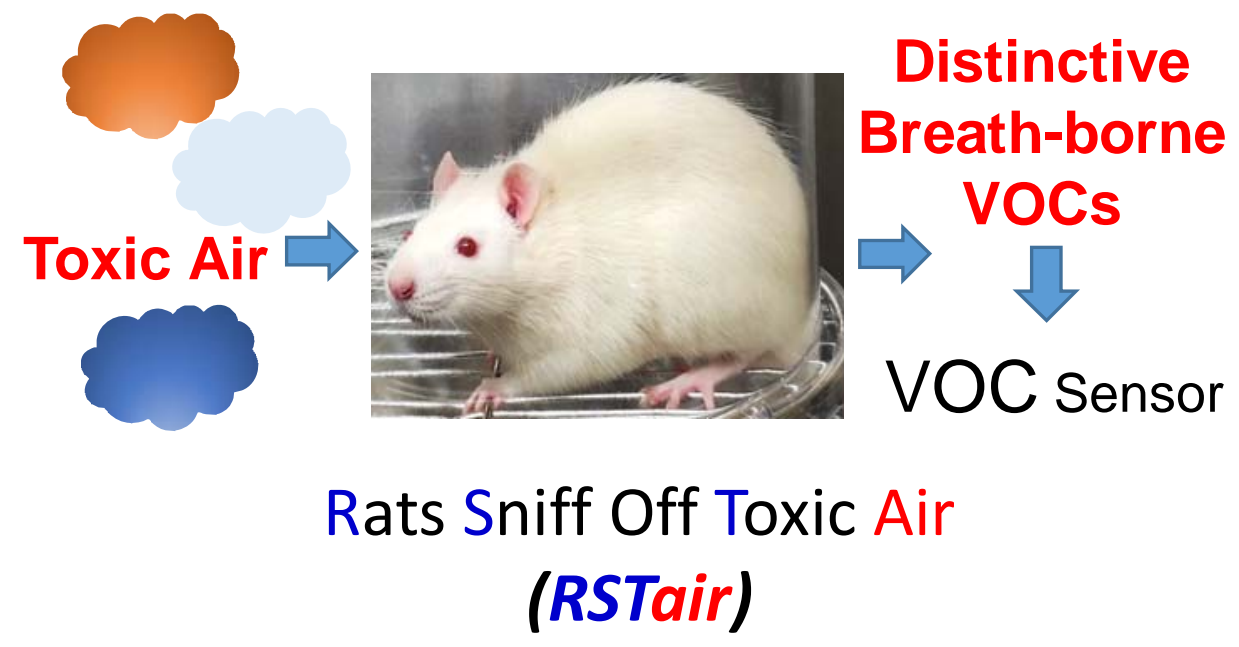

32

33

34

35 


\section{Abstract}

37 Breathing air is a fundamental human need, yet its safety, when challenged by 38 various harmful or lethal substances, is often not properly guarded. For example, air 39 toxicity is currently monitored only for single or limited number of known toxicants, 40 thus failing to fully warn against possible hazardous air. Here, we discovered that 41 within minutes living rats emitted distinctive profiles of volatile organic compounds 42 (VOCs) via breath when exposed to various airborne toxicants such as endotoxin, $\mathrm{O}_{3}$, 43 ricin, and $\mathrm{CO}_{2}$. Compared to background indoor air, when exposed to ricin or 44 endotoxin aerosols breath-borne VOC levels, especially that of carbon disulfide, were 45 shown to decrease; while their elevated levels were observed for $\mathrm{O}_{3}$ and $\mathrm{CO}_{2}$ 46 exposures. A clear contrast in breath-borne VOCs profiles of rats between different 47 toxicant exposures was observed with a statistical significance. Differences in 48 MicroRNA regulations such as miR-33, miR-146a and miR-155 from rats' blood samples revealed different mechanisms used by the rats in combating different air toxicant challenges. Similar to dogs, rats were found here to be able to sniff against toxic air by releasing a specific breath-borne VOC profile. The discovered science

52 opens a new arena for online monitoring air toxicity and health effects of pollutants.

54 Keywords: Online Monitoring Toxic Air, Rat, Volatile Organic Compound, 55 microRNA, 


\section{1. Introduction}

58 Polluted air is a complex mixture of various pollutants, including particulate 59 matter (PM), biologicals, and also gaseous substances such as $\mathrm{O}_{3}$ and NOx. Inhaling 60 these pollutants can cause a variety of serious health problems: respiratory and

61 cardiovascular diseases, and even death. ${ }^{1-2}$ For example, PM alone was shown to 62 have resulted in 4.2 million deaths in $2015{ }^{2-3}$ Exhibiting a positive correlation with 63 daily mean mortality, ground ozone exposure resulted in decreased lung function and 64 airway inflammation. ${ }^{4-5}$ In the meantime, exposure to pathogenic bioaerosols 65 including bacteria, fungi, virus, et al in the air can cause respiratory infections with 66 grave human and economic costs. ${ }^{6-9}$ Apart from these, there is a growing risk of 67 terrorist attacks by intentionally releasing biological and chemical agents into the air 68 to cause substantial civilian casualties. ${ }^{10-12}$ Apparently, inhaling unsafe air has 69 become an increasing health concern. Yet, in many high profile events, in addition to 70 the public sectors, the air being inhaled is not readily protected or properly guarded. 71 Real-time monitoring of air toxicity is of great importance, which however is a 72 long-standing significant challenge in the field.

For monitoring hazardous substances in the air, a variety of real-time online 75 monitoring methods have been previously developed or tested for individual 76 pollutants such as the PM and other chemicals. ${ }^{13-16}$ While for bioaerosols, the 77 adenosine triphosphate (ATP) bioluminescence technology, surface-enhanced Raman 78 spectroscopy (SERS), bioaerosol mass spectrometry (BAMS), ultraviolet 79 aerodynamic particle sizer (UVAPS) as well as silicon nanowire (SiNW) biosensor 80 were investigated and attempted over the years. ${ }^{17-19}$ It is well known that these 81 existing or developed technologies are mostly restricted to either single agent or 
82 overall microbial concentration levels without identifying species. In addition,

83 airborne pollutants and toxicity could vary greatly from one location to another ${ }^{20-21}$,

84 thus presenting location-specific air toxicity and health effects. Current

85 epidemiological or toxicological methods involving data analysis or animal and cells

86 experiments cannot provide in situ air toxicity information, accordingly failing to

87 represent the response at the time of exposure since biomarker levels evolve over time.

$88^{22}$ In addition, under certain scenarios (high profile meetings or locations) a rapid

89 response to air toxicity needs to be in place in order to protect the interests. However,

90 the response time is very demanding for an immediate effective counter-measure, for

91 example, usually several minutes can be tolerated. ${ }^{10,23}$ In many air environments,

92 multiple hazardous pollutants could also co-exist even with unknown ones at a

93 particular time, which makes protecting the air rather difficult, if not impossible,

94 using current technologies of species level detection and warning.

95

Previously, olfactory receptors of mouse cells for odors ${ }^{24}$, immune B cells ${ }^{25}$ for pathogen detections, and silicon nanowire sensor arrays for explosives ${ }^{26}$ were studied. Recently, a breath-borne biomarker detection system (dLABer) integrating rat's breath sampling, microfluidics and a silicon nanowire field effect transistor (SiNW FET) device has been developed for real-time tracking biological molecules in the breath of rats exposed to particulate matter (PM). ${ }^{27}$ The dLABer system was shown to be able to online detect interleukins-6 (IL-6) level in rat's breath, and capable of differentiating between different PM toxicities from different cities using the biomarker level. However, as observed in the study the production of protein biomarkers could significantly lag behind the pollutant exposure, thus falling short of providing a timely warning against toxic air. Nonetheless, exhaled breath is 
107 increasingly being used in biomarker analysis in both medical and environmental

108 health studies. ${ }^{28-30}$ In addition to protein biomarkers, a large number of volatile

109 compounds (e.g., nitric oxide, carbon monoxide, hydrocarbons) have been also

110 studied to assess health status and even developed for clinical diagnosis. ${ }^{31-32}$ For

111 example, ethane and n-pentane detected in the breath were linked to the in vivo level

112 of lipid peroxidation and oxidative stress ${ }^{33}$; breath-borne acetone was shown to

113 correlate with the metabolic state of diabetic patients. ${ }^{34}$ In addition, exhaled VOCs

114 have been used for the diagnosis of asthma, lung cancer and other diseases. ${ }^{35-37}$

115 Undoubtedly, breath-borne VOC has emerged as a promising biomarker for health or

116 environmental exposure monitoring.

117

118

120

121

123

124

125

Inspired by the dog sniff for explosive, the work here was conducted to investigate if we can use breath-borne VOCs from living rats to real-time monitor toxic air. Particularly, we wanted to investigate: 1) When rats are exposed to air toxicants, whether the VOC species and concentration in the exhaled breath change? If yes, how long does the change need to occur? 2) Are there any specific exhaled VOCs in response to different toxicants exposure including both chemical and biological agents? 3) To develop an online air toxicity analyzing system via real-time monitoring of exhaled VOCs of rats. The work here has demonstrated a great promise for online air toxicity monitoring using the method developed, and opened a new arena for studying health effects of air pollution.

\section{Materials and methods}

\subsection{Rat breeding}

The Jugular Vascular Catheterizations (JVC) rat model described in our previous 
132 study was used in this work. ${ }^{38}$ Weighing $200-240 \mathrm{~g}$ at an age of 10 weeks, a total of

13320 male Wistar rats with jugular vein catheterization operation and a $100 \mathrm{~mL} / \mathrm{min}$

134 inhalation rate were purchased from a local provider (Beijing Vital River Laboratory

135 Animal Technology Co., Ltd.). With about 1 centimeter out of the skin, a flexible

136 sterile catheter was embedded into the jugular vein and fixed on the back with staples.

137 Under a $12 \mathrm{~h}$ light/12 h dark cycle, all the rats were raised in an animal care facility

138 naturally with a normal chow diet. After 1 week of acclimation, the rats were

139 randomly divided into 5 groups (4 rats in each group) for the exposure of different air

140 toxicants. All animal experiments were approved by the Institutional Review Board of

141 Peking University and relevant experiments were performed in accordance with the

142 ethical standards (approval \# LA2019294).

143

144

145

146

147

148

149

150

151

152

153

154

155

156

\subsection{Preparation of toxic air}

In this work, four different exposure toxicants (ricin, endotoxin, ozone and carbon dioxide) and indoor air (as a background control) (5 groups) for rats were prepared for the exposure experiments. Ricin was extracted from the seeds of castor produced in Xinjiang, China, and prepared by Institute of Microbiology and Epidemiology, Academy of Military Medical Sciences in Beijing. The endotoxin was purchased from Associates of Cape Cod, Inc., USA. The ricin and endotoxin suspensions were prepared by vigorously vortexing $40 \mu \mathrm{g}$ of ricin or $50 \mathrm{ng}$ endotoxin per $\mathrm{ml}$ deionized (DI) water for $20 \mathrm{~min}$ at a vortex rate of $3200 \mathrm{rpm}$ (Vortex Genie-2, Scientific Industries Co., Ltd., USA). Detailed information about ricin preparation and exposure can be also found in another work. ${ }^{39}$ Here, ozone was generated by an ozone generator (Guangzhou Environmental Protection Electric Co., Ltd., China) using corona discharge method. The ozone was further diluted with indoor air for rat 
157 exposure experiments, and the ozone concentration in the exposed chamber was 158 approximately 5 ppm. Carbon dioxide was purchased from Beijing Haike Yuanchang 159 Utility Gas Co., Ltd., and diluted 20 times with indoor air to a concentration of about $1605 \%\left(5 \times 10^{4} \mathrm{ppm}\right)$. The major objective of this work was to study whether there will be 161 specific VOC release by rats when challenged with different toxicants, not specific 162 dose-response for each toxicant. Nonetheless, the selection of specific exposure levels 163 for different toxicants was provided and discussed in Supporting Information.

\subsection{Rats sniff off toxic air (RST $\left.T_{\text {air }}\right)$ system and experimental procedure}

166 To investigate whether we can use breath-borne VOCs from living systems to 167 real-time monitor toxic air, we have developed the system named as RSTair (Rats 168 Sniff Off Toxic Air). As shown in Figure 1 and Figure S1 (Supporting Information), 169 the system is composed of four major parts: toxicant generator, exposure chamber, 170 exhaled breath sampling and online VOC analysis. Indoor air was used as carrier gas 171 for generating toxicant aerosols (ricin and endotoxin) using a Collison Nebulizer (BGI, 172 Inc., USA) or diluting toxicants gas (ozone and carbon dioxide). The toxicant aerosol 173 or toxicant gas was introduced together with indoor air into the exposure chamber at a 174 flow rate of $1 \mathrm{~L} / \mathrm{min}$. As shown in Figure $\mathrm{S} 1$, a cage was used as the exposure 175 chamber which can allow rat's feces and urine to fall from below quickly so as to 176 reduce their influences on VOC analysis. In addition, teflon tubes and vales were also 177 applied to reducing adsorption loss of VOCs. For ricin and endotoxin, they are small 178 molecules and relevant particle loss on the aerosolization tubing could be negligible. 179 When performing the experiments, the rats were first placed in the exposure chamber. 180 Indoor air was continuously introduced into the chamber at a flow rate of $1 \mathrm{~L} / \mathrm{min}$ for 18110 minutes, then followed by each of tested toxicants together with indoor air at the 
182

183

184

185

186

187

188

189

190

191

192

193

194

195

196

197

198

199

200

201

202

203

204

205

206

same flow rate for about 10 minutes to conduct exposure tests.

For each toxicant experiment, the TVOC was first measured for the control (rat with indoor air at a flow rate of $1 \mathrm{~L} / \mathrm{min}$ ), then followed by the toxicant aerosol/gas exposure (rat + toxic air) at the same flow rate for $10 \mathrm{~min}$. Here, the photoionization detector (PID) (MOCON, Inc., USA) coupled with an air pump was used to real-time monitor TVOC at a flow rate of $0.6 \mathrm{~L} / \mathrm{min}$. After the exposure, the TVOC was continuously measured again using the PID sensor, reaching a relatively stable level approximately within 7-8 min. In the meantime, VOC samples were also collected both before (control) and after the toxicant exposure. A 3.2 L Silonite canister (Entech Instruments, Inc., USA) was used to collect VOC samples at the flow rate of 0.8 $\mathrm{L} / \mathrm{min}$ at least $10 \mathrm{~min}$ after the exposure test, and the VOCs species were further analyzed using a gas chromatograph-mass spectrometry/flame ionization detection (GC-MS/FID) system (Agilent Technologies, Inc., USA). A total of 117 VOC species were screened and quantified for all exposure tests using the GC-MS system. During the VOC sample collection, the PID sensor was switched to measure the indoor air TVOC levels. The detailed descriptions of the working principles of PID and VOC species analysis by GC-MS/FID are provided in Supporting Information. In this work, both TVOC and VOC species in the exposure chamber were analyzed for all the experiments: 1) when the rats were not in the chamber (background air); 2) rats in the chamber (before toxicant exposure) and rats in the chamber (after toxicant exposure). The air flows in and out of the exposure chamber were the same both for TVOC measurements and VOC collection. Based on the dimensions of the exposure chamber, the residence time of pollutants in the chamber was about 5 min under the experimental conditions, e.g., the air flow rate was about $1 \mathrm{~L} / \mathrm{min}$. We collected VOC 
207

208

209

210

211

212

213

214

215

216

217

218

219

220

221

222

223

224

225

226 samples at least 10 min after the toxicant exposure, therefore remaining secondary pollutants produced, if any, during the exposure tests such as $\mathrm{O}_{3}$ will be flushed out by the indoor air. For each toxicant, the above experiments were repeated four times with a different rat each time. Each rat (total four) either for toxicant or control exposure group experienced the exposure only once, not repeated exposures. For each of four tested toxicants, the same experiments were repeated. All tests were performed inside a Class 2 Type A2 Biological Safety Cabinet (NuAire, Plymouth, MN), and all exposure toxicants were ventilated out via the built-in and lab ventilation system.

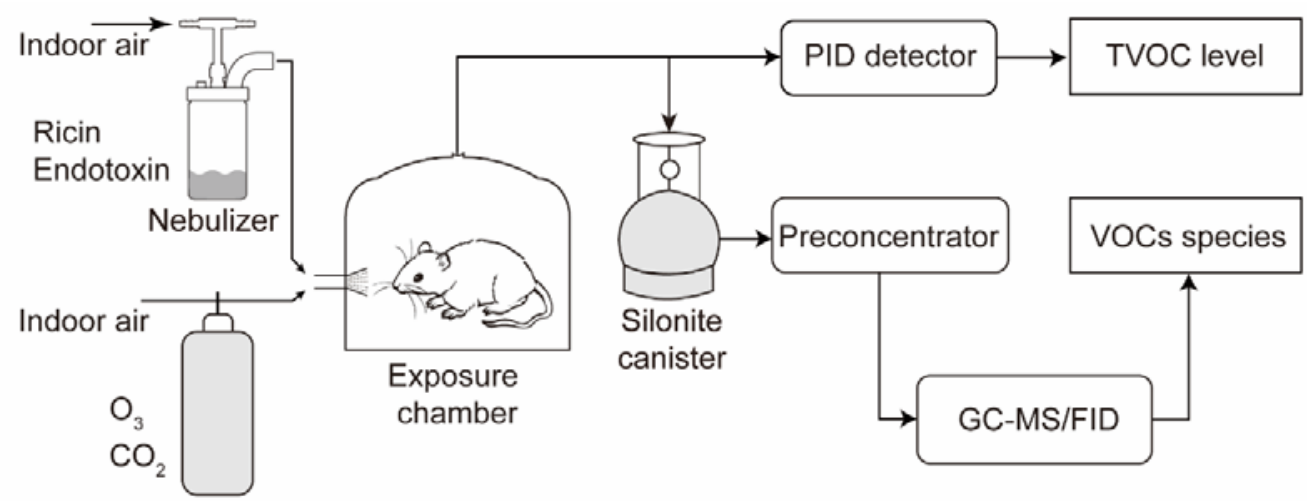

Figure 1. Rats sniff off toxic air (RSTair) system: different toxicants were introduced or aerosolized into the chamber for exposure. The VOCs from the rat placed in the chamber before and after the toxicant exposure for 10 min were analyzed by the PID directly and also by GC-MS/FID method coupled with a VOC sampler silonite canister. During the VOC collection and measurements by the PID, the toxicant exposure was terminated. Each time only one rat was placed into the chamber. For each toxicant, the experiment was independently repeated four times with a different 
227

228

229

230

231

232

233

234

235

236

237

238

239

240

241

242

243

244

245

246

247

248

249

250

251

rat each time.

\subsection{Blood microRNA detection}

Right before and $20 \mathrm{~min}$ after each 10-min toxicant exposure, $0.75 \mathrm{~mL}$ blood samples from rats were taken through the catheter using sterile syringes with $23 \mathrm{G}$ flat-end needles and kept at $-20{ }^{\circ} \mathrm{C}$ for microRNA analysis. The blood microRNAs in the blood samples such as miR-125b, miR-155, miR-146a, miR-21, miR-20b, miR-210, miR-122, and miR-33 were analyzed using a RT-qPCR array (Wcgene Biotech, Inc., China). Total RNAs in the blood samples, including microRNAs, were extracted using a Trizol reagent (Sigma Aldrich, Inc., USA) according to the manufacturer's instructions. Subsequently, the purified RNAs were polyadenylated through a poly(A) polymerase reaction and was then reversed-transcribed into complementary DNA (cDNA). TIANGEN® miRcute Plus miRNA First-Strand cDNA Kit (Code No. KR211) was used in the reverse transcriptional reaction system of total $10 \square \mu \mathrm{L}$, including $5 \square \mu \mathrm{L} \square 2 \mathrm{x}$ miRNA RT Reaction Buffer, $1 \square \mu \mathrm{L}$ miRNA RT Enzyme Mix and $4 \square \mu \mathrm{L}$ RNA sample. The reaction conditions are $40{ }^{\circ} \mathrm{C}$ for 60 mins and $95{ }^{\circ} \mathrm{C}$ for 3 mins. The cDNA was quantified in real-time SYBR Green RT-qPCR reactions with the specific microRNA qPCR Assay Primers. TIANGEN® miRcute Plus miRNA qPCR Kit (SYBR Green) (Code No. FP411) was used in the qPCR reaction system of total $10 \square \mu \mathrm{L}$, including $5 \square \mu \mathrm{L} \square 2 \mathrm{x}$ miRcute Plus miRNA PreMix (SYBR\&ROX), $0.2 \square \mu \mathrm{L}$ Forward Primer, 0.2 $\square \mu \mathrm{L}$ Reverse Primer, $1 \square \mu \mathrm{L}$ 50X ROX Reference Dye, $1 \square \mu \mathrm{L}$ DNA Sample and 2.6 $\square \mu \mathrm{L} \mathrm{ddH}_{2} \mathrm{O}$. The cycling conditions were $95{ }^{\circ} \mathrm{C}$ for 15 min, followed by 40 cycles at $94{ }^{\circ} \mathrm{C}$ for 20 s, $60{ }^{\circ} \mathrm{C}$ for $15 \mathrm{~s}$ and $72^{\circ} \mathrm{C}$ for 30 s. The primers used for qPCR are presented in Table S1 (Supporting Information). 


\section{Statistical analysis}

254 In this study, the TVOC levels for all samples detected by the PID sensor were 255 not normally distributed, while their TVOC change rates were. The TVOC change 256 rate was calculated by dividing the TVOC level after exposure using the TVOC level 257 before exposure. Therefore, the Mann-Whitney rank sum test was used to analyze the 258 differences in TVOC levels before and after each toxicant exposure, and t-test was 259 used to analyze the differences in TVOC change rates between each toxicant exposure 260 group and the control group (indoor air). For individual VOC concentrations by 261 GC-MS/FID, the paired t-test was used to analyze differences for each VOC species 262 before and after the exposure. The software Canoco 4.5 was used to visualize the 263 VOC profile distance and relatedness between the samples of different groups using 264 the principal component analysis (PCA). Besides, the concentrations of micro-RNAs 265 in blood samples from different rat groups were determined by RT-qPCR. For the 266 group exposed to carbon dioxide, blood samples were only taken from two rats 267 (before and after the 10-min exposure) because of the catheter blockage (unable to 268 draw bloods) for the other two. For the other three groups, blood samples were 269 obtained for all four rats. The differences between micro-RNA levels in blood samples 270 before and after the exposure in one group were analyzed using a paired t-test (data 271 exhibited a normal distribution) or Wilcoxon signed rank test (data did not follow a 272 normal distribution). The outliers for normally distributed data were examined and 273 eliminated by a Grubbs test. All the statistical tests were performed via the statistical 274 component of SigmaPlot 12.5 (Systat Software, Inc., USA), and a $p$-value of less than 2750.05 indicated a statistically significant difference at a confidence level of $95 \%$. 


\section{Results and discussion}

279

280

281

282

\subsection{TVOC monitoring for the toxicants exposure}

As described in the experimental section, four toxicants (ricin, endotoxin, ozone and carbon dioxide) and indoor air (as a background control) were used for inhalation exposure in rats. For each group, the TVOC levels of only 3 rats (PID instrument/software failure for one out of 4 rats) were shown in Figure 2. The indoor air background TVOC was found to be less than $0.04 \pm 0.02 \mathrm{ppm}$. After one rat was placed in the exposure chamber, the TVOC level in the cage was shown to first gradually increase, then reach a relatively stable level after about 500 seconds. The TVOC level before the exposure (rat + indoor air) when one rat was in the chamber was about $2 \mathrm{ppm}$, except for the $\mathrm{CO}_{2}$ group it was about 0.5-0.8 ppm (These differences, if any, applied to both before and after exposure in one test, thus presenting no influences on the same experiments). The differences in TVOC levels for indoor air exposures (different times: "before" and "after", but the same indoor air) were small (the average change rate was about $-4 \% \pm 1.4 \%$ (95\% confidence interval)), although the Mann-Whitney Rank Sum Test showed that for each of the rats, the difference (over some time for the indoor air) was significant $(p$-value<0.001). The background indoor air TVOC levels were $1.22-5.1 \%$ (detected) of the chamber TVOC with rats together with indoor air or other toxicants). The fluctuations were taken into account for each toxicant exposure test. Nonetheless, the fluctuations, if any, from background indoor air had minor impacts on the TVOC levels measured for rats' exposure tests. The change rates $(n=3)$ of the control group (indoor air) then served as the reference for other toxicant exposures in the statistical analysis. During the indoor air experiment, the rats were seen to carry out normal life activities in the exposure 
302 chamber, and correspondingly the TVOCs in the chamber were shown to remain

303 relatively stable.

304

305

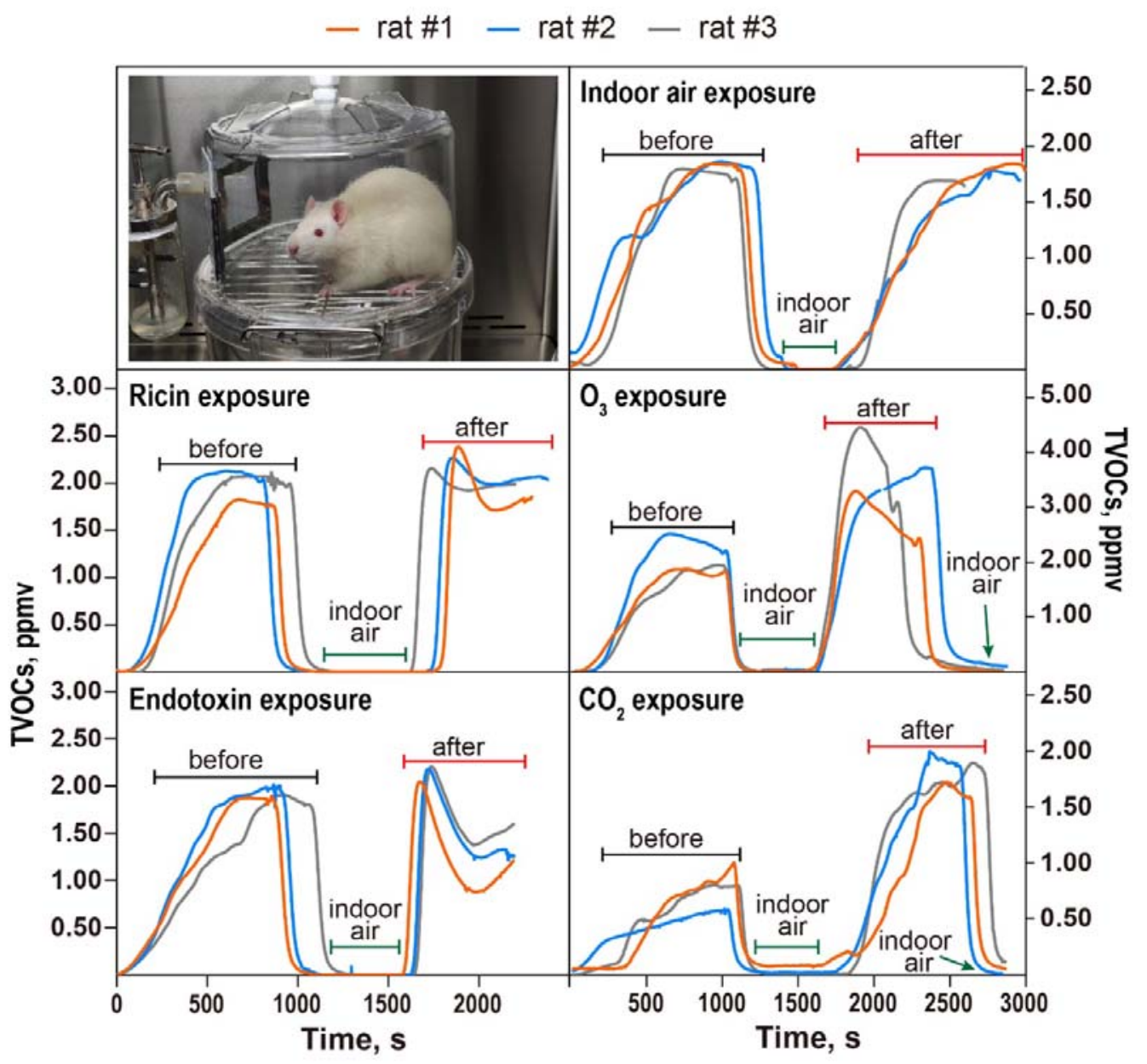

307 Figure 2. Real-time continuous measurements of exhaled TVOC levels in the

308 chamber when rats were exposed to different toxicants via inhalation for 10 mins:

309 Indoor air, ricin, endotoxin, $\mathrm{O}_{3}$ and $\mathrm{CO}_{2}$. During the exposure processes, the PID

310 sensor was turned off. Data lines (measurement time was $1000 \mathrm{~s}$ ) represent results

311 from three individual rats $(\# 1, \# 2, \# 3)$ before or after exposure to each of the air

312 toxicants (aerosolized amounts described in the experimental section) tested. Each 
313 exposure test was independently repeated with four rats from the same group (PID

314 instrument/software failure for one rat).

In contrast, the TVOC levels were shown to vary greatly with different toxicant exposures as shown in Figure 2. For example, when rats were exposed to the

319 aerosolized ricin, the TVOC level was observed to exhibit an average change rate of $320-3 \% \pm 1.6$. Compared to the control group (indoor air + rat before the exposure) shown 321 in Figure 2, the difference of the TVOC change rate was not significant for the ricin 322 exposure (t-test, $p$-value $=0.426)$. For ricin exposure, its concentration $(40 \mu \mathrm{g} / \mathrm{mL}$ 323 suspension aerosolized) might be too low in aerosol state after the aerosolization from 324 the liquid to produce a detectable response from the rats. It was previously reported 325 that $0.1 \mathrm{mg} / \mathrm{mL}$ ricin solution was used for aerosolization and subsequent exposure to 326 mice (Ref \# 5, Supporting Information). After 30 minutes ricin aerosol exposure, the 327 exposed mice became poisoned. The concentration of ricin used in this experiment 328 was lower and the exposure time was shorter, therefore the toxicity reaction may be 329 mild. In contrast to the ricin exposure, however we observed a different phenomenon 330 for the endotoxin $(50 \mathrm{ng} / \mathrm{mL}$ aerosolized) tests as shown in Figure 2. Upon the 331 endotoxin exposure, the TVOC level was observed to first increase, and then 332 decreased to a level that was about $21-46 \%$ below the pre-exposure level after four 333 minutes (Mann-Whitney Rank Sum Test, all p-values $<0.001$ ). Compared to the 334 control group (indoor air + rat), the difference of the TVOC change rate was 335 statistically significant for endotoxin (t-test, $p$-value $=0.0147$ ). The observed 336 differences from the ricin and endotoxin exposures could be due to different 337 mechanisms initiated by different substances involved. Ricin is derived from plant, 
338 while endotoxin is from Gram-negative bacterial membrane. They could interact

339 differently with relevant human respiratory or other body cells. Nonetheless, for both

340 ricin and endotoxin, they were probably causing health effects by immuno-toxicity,

341 while $\mathrm{O}_{3}$ and $\mathrm{CO}_{2}$ both induce harm first by chemical manners.

After exposure to gaseous toxicants such as ozone and carbon dioxide, the levels

344 of TVOCs in the exposure chamber with rats were observed to have increased

345 significantly, as observed in Figure 2. As can be seen from the figure, the TVOC

346 levels has increased for about $44-110 \%$ for ozone and about $109-265 \%$ for carbon

347 dioxide exposure (Mann-Whitney Rank Sum Test, all $p$-values $<0.001$ ). The t-test

348 showed that differences of the TVOC change rates of both ozone and $\mathrm{CO}_{2}$ exposures

349 compared to the control group (indoor air) were statistically significant

350 ( $p$-value $=0.0219$ and 0.0296 , respectively). These data indicated that rat exposure to

351 both ozone and $\mathrm{CO}_{2}$ has resulted in significant elevations of TVOCs, suggesting rats

352 were actively responding to the exposure challenges. The behavior observation from a

353 video also indicated that rats after the exposure to $\mathrm{O}_{3}$ seemed to be suffering from the

354 challenge (Video S1, Supporting Information).

\subsection{Changes in exhaled VOCs after exposure to different toxicants}

357 Using GC-MS/FID method, a total of 31 different VOCs out of 117 screened

358 were detected and shown in Figure S2 (Supporting Information) for background

359 indoor air with and without rats. Among detected VOCs as shown in Figure S2

360 (Supporting Information), the VOCs with the highest concentrations in indoor air

361 were n-hexane, ethyl acetate and acetone. When rats were placed in the exposure

362 chamber (one rat at each time), the most abundant VOC species was detected to be 
acetone, which was about 4 times more than that of the indoor air background.

364 Statistical tests found that the concentrations of ethylene and ethane in the chamber

Namely, when rats' breath with specific higher or lower VOC species replaced

368 equivalent indoor air inside the chamber, diluting effects for higher indoor VOC

369 species and enhancing effects for lower indoor VOC species could take place.
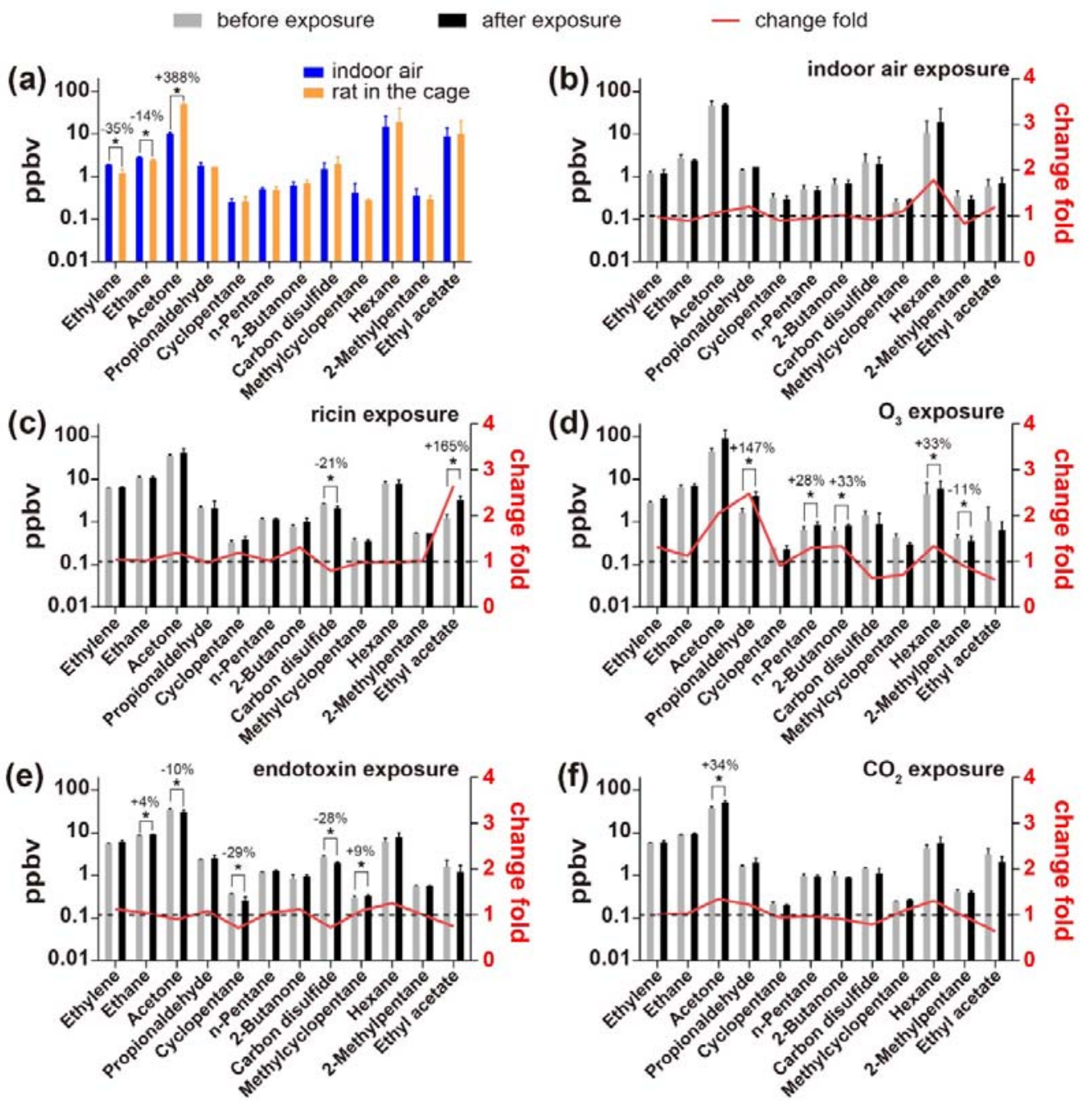

371 Figure 3. Differentiations of VOC species from indoor air and those from the rats' 
$373 \mathrm{CO}_{2}$. The red lines show that the average change ratios of every toxicant calculated by

374 the level after the exposure divided by the level before exposure (right axis). The

375 dotted line is the baseline with a change ratio of 1 . Percentages refer to specific VOC

376 percentage change before and after the exposure. Values represent averages and

377 standard deviations from three different rats. "*” indicates a significant difference at

$378 \quad p$-value $<0.05$.

379

380

381

382

383

384

385

386

387

388

389

390

391

392

393

394

395

396

397

Differentiations of VOC species from the rat's exhaled breath under different toxicants exposures were also shown in Figure 3. There were no significant differences in the concentrations of any VOCs before and after the exposure for the control group, i.e., indoor air (t-test, $p$-value $=0.05)$. This suggests that indoor air is relatively less toxic at a level that is unable to detect a VOC change. In contrast, specific VOC species had experienced significant changes when rats were exposed to ricin, endotoxin, $\mathrm{O}_{3}$ and $\mathrm{CO}_{2}$ as observed from Figure 3. For example, exposure to ricin caused significant higher concentration of ethyl acetate (183\% higher), while lower concentration of carbon disulfide (22\% lower). As shown in Figure 3, after the endotoxin exposure process, concentrations of five VOC species: ethane, acetone, cyclopentane, carbon disulfide and methylcyclopentane were shown to be significantly different with those of before the exposure (t-test, all $p$-values $<0.05$ ). As can be seen from the results of the ozone exposure group in Figure 3, the concentrations of propionaldehyde, pentane, 2-butanone, hexane and 2-methylpentane exhibited significant differences before and after exposure (t-test, all p-values $<0.05$ ), in which all the VOCs except 2-methylpentane were elevated. In comparison, rat exposure to $\mathrm{CO}_{2}$ resulted in acetone level increase by $34 \%$ (t-test, $p$-value $=0.0016$ ). These data suggest that exposure to different toxicants had led to production of 
398 different profiles of VOC species in addition to their level changes.

399

400

401

402

403

404

405

406

407

408

409

410

411

412

413

414

415

416

417

418

419

420

421

422

\subsection{Detection of micro RNAs in Blood Samples}

To further explore the VOC response mechanism of rats to toxicants exposure, microRNAs (miRNA) in the blood samples were examined by an RT-qPCR assay. Fold-changes in microRNA levels after toxicants exposure were shown in Table S2 (Supporting Information). The level of miR-33 in the blood of rats was shown to be significantly lower than that before ricin exposure ( $p$-value $<0.05)$; after exposure to ozone, miR-146a level in the blood samples of rats was significantly higher than those before the exposure $(p$-value $<0.05)$, while miR-155 was significantly lower than that before the exposure $(p$-value $<0.05)$. For other microRNAs as listed in Table S2, the changes seemed to be insignificant (t-test, $p$-values $>0.05$ ).

As observed from Figure 4, PCA results revealed a clear contrast in breath-borne VOC profiles of rats between different toxicants exposures. The VOC profiles of the ozone exposure group was very different from that of the control group (indoor air) and the VOCs profile of the ricin exposure group was the closest to that of the control group, which agreed with TVOC level and VOC species profiles obtained above. Overall, the experiments showed that rats responded differently to different toxicants by releasing different VOC species owing to different mechanisms of toxicity: ozone caused significant increases in various breath-borne VOCs; while endotoxin exposure generally decreased the releasing of VOCs; and ricin and carbon dioxide exposure resulted in one or two significant VOC species changes. In general, the results of qualitative and quantitative analysis by the GC-MS/FID method agreed with the TVOC level monitored by the PID sensor. 
423

424 Figure 4. PCA ordinations of exhaled breath-borne VOCs profiles under exposures to

425 different toxicants: ricin, endotoxin, $\mathrm{O}_{3}, \mathrm{CO}_{2}$ and control (indoor air). $\mathrm{PC} 1$ and PC2

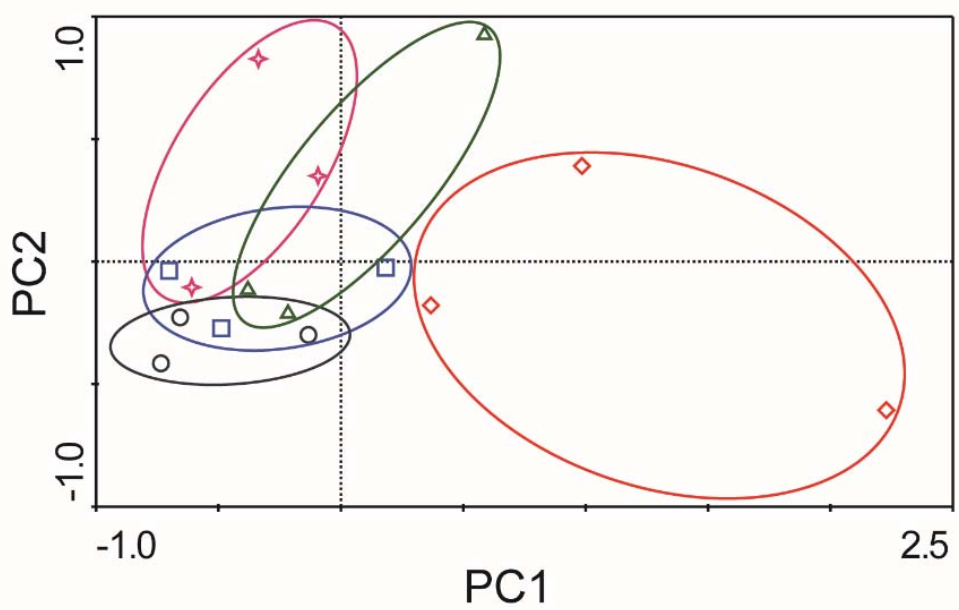

\section{Exposure group}

․ Ricin

$\diamond$ Endotoxin

$\diamond \mathrm{O}_{3}$

$\triangle \quad \mathrm{CO}_{2}$

○ Indoor air

426

427

428

429

430

431

432

433

434

435

436

437

438

439

440

are the first and second principal components. The VOCs species involved in the PCA

analysis were the 12 species which were shown to have undergone changes after each

toxicant exposure. Data presented in the figure were from three independent rats exposed to each toxicant.

As observed from Figure 3, exposure to ricin caused $183 \pm 143 \%$ higher concentration of ethyl acetate, while $22 \pm 8 \%$ lower concentration of carbon disulfide. It was previously reported the concentration of ethyl acetate was significantly higher in exhaled breath from people with cancer compared to the healthy group. ${ }^{40,41}$ In addition, in vitro experiments have shown the human umbilical vein endothelial cells (HUVEC) can produce ethyl acetate, which is presumably generated by a reaction of ethanol with acetic acid. ${ }^{42}$ It was demonstrated that ricin is not only responsible for the ricin intoxication through ribosomal inactivation and subsequent inhibition of protein synthesis and cell death, but also shows endothelial toxicity by acting as a natural disintegrin binding to and damaging human endothelial cells. ${ }^{43}$ Therefore, the 
441 toxicity of ricin on the endothelial cells might be the source of the higher

442 concentration of ethyl acetate observed in this work. As a disease biomarker, carbon

443 disulfide was observed in the exhaled breath. ${ }^{44-45}$ Recently, it was suggested that the

444 carbon disulfide may be generated endogenously and play a role as a bioregulator. ${ }^{46}$

445 Here, we observed that exposure to both ricin and endotoxin resulted in lower levels

446 of breath-borne carbon disulfide compared to the control.

447

448

449

450

451

452

453

454

455

456

457

458

459

460

461

462

463

464 465 generated by peroxidation of $\omega-3$ polyunsaturated fatty acids. ${ }^{33}$ In addition to ethane,

For $\mathrm{CO}_{2}$ and endotoxin exposure, the observation for acetone was the opposite as shown in Figure 3. Acetone in exhaled breath was widely investigated in many studies as an important biomarker related to blood glucose and diabetes. ${ }^{34,47}$ Acetone is produced in the fatty acids metabolism by hepatocytes via decarboxylation of excess acetyl coenzyme A (Acetyl-CoA), and then oxidized via the Krebs cycle in peripheral tissue. ${ }^{48}$ As shown in Figure 3, the acetone level increased by $34 \pm 9 \%$ as a result of $\mathrm{CO}_{2}$ exposure, suggesting $\mathrm{CO}_{2}$ caused hypoxia in rats, and led to increased respiration from rats. These increases in acetone level corresponded to TVOC level increase as determined by the PID sensor after the exposure to $\mathrm{CO}_{2}$. However, when exposed to endotoxin, the acetone level in the exposure chamber decreased by about $10 \pm 6 \%$, indicating that the respiration of the rats may be attenuated by the exposure of endotoxin. Clearly, the involved mechanisms by which endotoxin and $\mathrm{CO}_{2}$ cause health effects to rats could be very different.

As observed in Figure 3, the increase of ethane level by endotoxin exposure suggested that lipid damage was induced by oxidative stress in the rat's body since ethane is acknowledged as a marker of lipid peroxidation and described to be 
466 the increase of methylcyclopentane level as shown in Figure 3 might also be the result

467 of the endotoxin exposure. Endotoxin has been shown to trigger inflammation through

468 its interaction with the TLR4/CD14/MD2 receptor and then initiates a signal cascade.

469 This reaction correspondingly results in the activation of transcription factor such as

470 NF- $\kappa$ B leading to the production of pro-inflammatory cytokines and type 1 interferons

471 (IFNs), and finally results in systemic inflammatory response syndrome. ${ }^{49}$ In general,

472 in terms with the average fold changes, the concentration of total VOCs in the exhaled

473 breath was relatively lower after the endotoxin exposure, which agreed with the

474 results of TVOC obtained by the PID sensors.

475

476 In addition to these biologicals, we have also shown that exposure to chemicals

477 such as ozone and $\mathrm{CO}_{2}$ also resulted in in-vivo changes in VOC levels. From the fold

478 changes of various VOC species such as propionaldehyde, N-pentane, 2-Butanone,

479 and Hexane, the ozone exposure has resulted in an overall increase of VOCs in rats'

480 exhaled breath, which agreed with the TOVC monitoring shown in Figure 2 by the

481 PID sensors. It was previously indicated that increase in propionaldehydes, further

482 products of lipid peroxidation, indicated more severe oxidative damage in rats

483 following exposure to ozone. ${ }^{50}$ Here, we also showed that after exposure to ozone

484 changes in specific breath-borne VOCs and also certain miRNA regulations were

485 detected. Ozone was described as a strong oxidizing agent, and can cause intracellular

486 oxidative stress through ozonide and hydroperoxide formation. ${ }^{51}$ The mechanism of

487 ozone oxidative damage involves the activation of $\mathrm{Nrf} 2$, heat shock protein 70 , and

488 NF-kB, thus increasing expression of a range of proinflammatory cytokines such as

489 TNF $\alpha$ and interleukin $1 \beta$, and chemokines such as interleukin $8 .^{52}$ The results above

490 show that regardless of toxicant types breath-borne VOCs from rats experienced in 
491 vivo changes.

492

493

Results of miRNAs from rats' blood as shown in Table S4 revealed different

494

mechanisms by rats when exposed to various types of toxicants. miRNAs are short

non-coding RNA sequences that regulate gene expression at the posttranscriptional

496 level; and many miRNAs have already been identified to influence physiological

497 processes such as immune reaction, adaptation to stress, and widely investigated in

498 environmental exposure studies. ${ }^{53}$ Among these microRNAs, miR-125b, miR-155,

499 miR-146a, and miR-21 are mainly shown to regulate oxidative stress and

500 inflammatory processes in vivo, and widely investigated in air pollution related

501 studies. ${ }^{53-54}$ For example, among them, miR-155 has a positive regulation function,

502 and the other three are negative regulation. ${ }^{55-56}$ However, in this study, the ozone

503 exposure resulted in decreased levels of miR-155 (t-test, $p$-value $<0.05$ ), which are

504 different from previous reports in the literature. ${ }^{55}$ The difference could be due to

505 different exposure toxicant, i.e., ozone used here, leading to acute lung damages

506 compared to mild airway inflammation or asthma problems in other studies. Previous

507 studies have shown that miR-20b and miR-210 are hypoxia regulators in animals, and

508 miR-122 and miR-33 are mainly responsible for regulating lipid metabolism and

509 glucose metabolism in the body. ${ }^{57-58}$ However, these microRNAs, except for the

510 decreased level of miR-33 and increased level of miR-146a caused by ricin and ozone

511 exposure, respectively, were shown to have not undergone significant changes in this

512 study after the exposures to four different toxicants ( $p$-values $=0.05$ ). The possible

513 reason may be that microRNAs act as post-transcriptional regulators by degrading

514 mRNA or inhibiting their translation, thus failing to respond in a timely manner

515 during short-term exposure (blood samples taken 20 min after the 10-min exposure ). 
516 To further understand the problem, a yeast model is currently being used to fully

517 investigate the mechanisms underlying the miRNA regulation when exposed to the

518 toxicants used here. Nonetheless, these results here reflected that exposure to the

519 toxicants led to specific miRNAs either up- or down-regulated. On the other hand, the

520 results here also suggest, especially for those no changes observed for the miRNAs,

521 higher toxicant level or specific longer time might be needed to allow miRNA

522 regulation change to occur.

523

524

525

526

527

529

530

531

532

533

534 of existing VOCs. ${ }^{59}$ Therefore, cell or tissue injuries caused by external toxicants

535 exposure also can alter the exhaled VOCs profile by disturbing the normal process. ${ }^{60}$

536 The exact toxic effect mechanism as observed from this work could vary from one

537 toxicant to another. For some pollutants such as endotoxin and ricin, there are specific

538 receptors to recognize them and then start the chain of responses or reactions. ${ }^{49,61}$

539 Among these various mechanisms, the ROS (reactive oxygen species) and oxidative

540 stress are recognized to be the central and the common mechanism in various forms of 
541 pathophysiology, as well as the health effect of various air pollutants including

542 ambient particulate matter (PM). ${ }^{1,62-63}$ Oxidative stress is essentially a compensatory

543 state of the body and can trigger redox-sensitive pathways leading to different

544 biological processes such as inflammation and cell death. ${ }^{51,64}$ For example, the strong

545 oxidants such as ozone might cause oxidative stress through direct effects on lipids

546 and protein ${ }^{65-66}$, which mostly caused the generation and release of hydrocarbons and

547 aldehydes, such as ethane, ethylene, and propionaldehyde. ${ }^{50,67}$ While carbon dioxide

548 tends to make the redox balance tilted toward the reduction side by reducing oxygen

549 supply and thus influencing the energy metabolism in cells. ${ }^{68-70}$ For ricin and

550 endotoxin exposure, the underlying mechanisms seem to be different from ozone and

$551 \mathrm{CO}_{2}$, and they could cause oxidative stress indirectly through the activation of

552 intracellular oxidant pathways. Nonetheless, all toxicants share a common effect of

553 disrupting the redox balance, and thus interfere with normal biochemical reactions or

554 cause material damages in cells, accordingly changing the VOC profile released into

555 the breath. As discussed above, in this work, the VOCs profile of rats changed

556 significantly after exposure to different toxicants. Therefore, regardless of toxicant

557 types, breath-borne VOCs from the rats seem to be capable of serving as a proxy for

558 real-time monitoring air toxicity. It was reported about 100 years ago that three mice

559 were also carried on all British submarines for sensing small leakage of gasoline as

560 the rats could squeak to notify the crew (Figure S3, Supporting Information). Some

561 previously detected VOCs such as hexane, pentane, acetaldehyde, butanone, and

562 acetone from rat's exhaled breath ${ }^{71,72}$ were also detected in this work. Nonetheless,

563 due to variations in rat breed, experimental conditions, VOC sampling and analysis

564 methods, it is rather difficult to exactly compare the VOCs from rat's exhaled breath

565 across different studies. There might be some breath-borne VOC species not identified 
566 yet for the rats used here. Interestingly, rat L6 skeletal muscle cells cultivated with

567 a-MEM containing 10\% FCS were shown to release 7 VOC species and uptake 16

568 VOC species. ${ }^{73}$ Similarly, the increased VOCs detected here from rat's exhaled breath

569 might be released from lung cells or other impacted ones by the exposure. On another

570 front, previous work showed that changes were also detected in breath-borne VOCS

571 from people with upper respiratory infections compared to the health individuals (Ref

$572 \# 7$, Supporting Information). All these studies and data support the results and validity

573 of our work from various aspects. For improving $R S T_{\text {air }}$ performance, GC-MS can be

574 also replaced using the Proton Transfer Reaction-Mass Spectrometry (PTR-MS) for

575 fast online VOC species analysis. By using this discovered fundamental science, the

576 invented RSTair system here showed its great promise of revolutionizing the air

577 toxicity monitoring, and providing significant technological advances for air security

578 in related fields such as military defense, customs, counter-terrorism and security

579 assurances for important events or special locations. 
580

581 Figure 5. Proposed mechanisms of toxic effects and VOCs releasing in rats when

582 exposed to the environmental toxicants via inhalation. The black arrows represent the

583 toxic effects of different toxicants and the possible pathways of VOCs generation. The

584 blue arrows stand for the principle and working process of the invented RSTair system

585 for real-time air toxicity monitoring. The corresponding references cited are: (1) ${ }^{59}$;

(2) ${ }^{66}$; (3) ${ }^{63}$; (4) ${ }^{48}$; (5) ${ }^{42}$; (6) ${ }^{48,70}$.
587

588

589

590 levels for different toxicant, experimental setup for RSTair system, indoor air

591 background VOCs, Photo of UK postcard for three mice carried on British

592 submarines, Primers used for RT-qPCR analysis of microRNA and mi-RNA

593 expression level changes after exposure, video of rat after exposed to ozone were 
594 provided as Supporting Information.

595

\section{Acknowledgements}

597 This study was supported by the NSFC Distinguished Young Scholars Fund

598 Awarded to M. Yao (21725701), and the Ministry of Science and Technology

599 (2016YFC0207102).

600

601 Conflict of interests

602 The authors declare no competing financial interest.

603 


\section{References}

605 1. Brook, R. D.; Rajagopalan, S.; Pope, C. A., III.; Brook, J. R.; Bhatnagar, A.;

606 Diez-Roux, A., V.; Holguin, F.; Hong Y.; Luepker, R., V.; Mittleman, M. A.; Peters, A.;

607 Siscovick, D.; Smith, S. C., Jr.; Whitsel, L.; Kaufman, J. D. , Particulate matter air 608 pollution and cardiovascular disease an update to the scientific statement from the 609 American Heart Association. Circulation 2010, 121 (21), 2331-2378.

610 2. Cohen, A. J.; Brauer, M.; Burnett, R.; Anderson, H. R.; Frostad, J.; Estep, K.; 611 Balakrishnan, K.; Brunekreef, B.; Dandona, L. Dandona, R.; Feigin, V.; Freedman, G.; 612 Hubbell, B.; Jobling, A.; Kan, H.; Knibbs, L.; Liu, Y.; Martin, R.; Morawska, L.; C 613 Pope, C. A., III.; Shin, H.; Straif, K.; Shaddick, G.; Thomas, M.; Dingenen, R. v.; 614 Donkelaar, A. v.; Vos, T.; Murray, C. J. L.; Forouzanfar, M. H. Estimates and 615 25-year trends of the global burden of disease attributable to ambient air pollution: an 616 analysis of data from the Global Burden of Diseases Study 2015. Lancet 2017, 389 617 (10082), 1907.

618 3. GBD 2015 Risk Factors Collaborators. Global, regional, and national 619 comparative risk assessment of 79 behavioural, environmental and occupational, and 620 metabolic risks or clusters of risks, 1990-2015: a systematic analysis for the Global 621 Burden of Disease Study 2015. Lancet 2016, 388 (10053), 1659-1724.

622 4. EPA, U. S., Integrated Science Assessment (ISA) of Ozone and Related 623 Photochemical Oxidants (Final Report, Feb 2013). Agency, U. S. E. P., Ed. 624 Washington, DC, 2013; Vol. EPA/600/R-10/076F.

625 5. Jerrett, M.; Burnett, R. T.; Pope, C. A. III.; Ito, K.; Thurston, G.; Krewski, D.; 626 Shi, Y.; Calle, E.; Thun, M. Long-term ozone exposure and mortality. N. Engl. J. Med. $6272009,360(11), 1085-1095$.

628 6. Thompson, W. W.; Shay, D. K.; Weintraub, E.;Brammer, L.; Cox, N.; Anderson, 
629 L. J.; Fukuda, K. Mortality associated with influenza and respiratory syncytial virus in 630 the United States. JAMA 2003, 289 (2), 179-186.

631 7. Jones, R. M.; Brosseau, L. M. Aerosol transmission of infectious disease. J. 632 Occup. Environ. Med. 2015, 57 (5), 501-508.

633 8. Fernstrom, A.; Goldblatt, M. Aerobiology and its role in the transmission of 634 infectious diseases. $J$ Pathog 2013, Article ID: 493960, doi: 635 http://dx.doi.org/10.1155/2013/493960.

636 9. Yu, I. T. S.; Li, Y.; Wong, T. W.; Tam, W.; Chan, A. T.; Lee, J. H.W.; Leung, D. Y.

637 C.; Ho, T. Evidence of airborne transmission of the Severe Acute Respiratory 638 Syndrome Virus. N. Engl. J. Med. 2004, 350 (17), 1731-1739.

639 10. Green, M. S.; LeDuc, J.; Cohen, D.; Franz, D. R. Confronting the threat of 640 bioterrorism: realities, challenges, and defensive strategies. Lancet Infect Dis 2019, 19 641 (1), e2-e13.

642 11. Okumura, T.; Takasu, N.; Ishimatsu, S. Miyanoki, S.; Mitsuhashi, A.; Kumada. K.; 643 Tanaka, K.; Hinohara, S. Report on 640 Victims of the Tokyo subway Sarin attack. 644 Ann. Emerg. Med. 1996, 28 (2), 129-135.

645 12. Jernigan, D. B.; Raghunathan, P. L.; Bell, B. P.; Brechner, R.; Bresnitz, E. A.; 646 Butler, J. C.; Cetron, M.; Cohen, M.; Doyle, T.; Fischer, M.; Greene, C.; Griffith, K. 647 S.; Guarner, J.; Hadler, J. L.; Hayslett, J. A.; Meyer, R.; Petersen, L. R.; Phillips, M.; 648 Pinner, R.; Popovic, T.; Quinn, C. P.; Reefhuis, J.; Reissman, D.; Rosenstein, N.; 649 Schuchat, A.; Shieh, W.; Siegal, L.; Swerdlow, D. L.; Tenover, F. C.; Traeger, M.; 650 Ward, J. W. Weisfuse, I.; Wiersma, S.; Yeskey, K.; Zaki, S.; Ashford, D. A. Perkins, B. 651 A. Ostroff, S.; Hughes, J.; Fleming, D.; Koplan, J. P.; Gerberding, J. L. and the 652 National Anthrax Epidemiologic Investigation Team. Investigation of 653 bioterrorism-related anthrax, United States, 2001: epidemiologic findings. Emerg. 
654 Infect. Dis. 2002, 8 (10), 1019.

655 13. Marć, M.; Tobiszewski, M.; Zabiegała, B.; Guardia, M. d. 1.; Namieśnik, J.

656 Current air quality analytics and monitoring: A review. Anal. Chim. Acta 2015, 853,

$657 \quad 116-126$.

658 14. Sameenoi, Y.; Koehler, K.; Shapiro, J.; Boonsong, K.; Sun, Y.; Collett, J. Jr.;

659 Volckens, J.; Henry, C. S. Microfluidic electrochemical sensor for on-line monitoring

660 of aerosol oxidative activity. J. Am. Chem. Soc. 2012, 134 (25), 10562-10568.

661 15. Ishihara, S.; Azzarelli, J. M.; Krikorian, M.; Swager, T. M. Ultratrace detection of

662 toxic chemicals: triggered disassembly of supramolecular nanotube wrappers. J. Am.

663 Chem. Soc. 2016, 138 (26), 8221-8227.

664 16. Azzarelli, J. M.; Mirica, K. A.; Ravnsbæk, J. B.; Swager, T. M. Wireless gas

665 detection with a smartphone via rf communication. Proc. Natl. Acad. Sci. 2014, 111

666 (51), 18162.

667 17. Jung, J. H.; Park, S. Y.; Lee, J. E.; Lee, B. U.; Bae, G. N. Distinguishing biotic

668 and abiotic particles using an ultraviolet aerodynamic particle sizer for real-time

669 detection of bacterial bioaerosols. Environ. Eng. Sci. 2012, 29 (9), 866-874.

670 18. Schwarzmeier, K.; Knauer, M.; Ivleva, N. P.; Niessner, R.; Haisch, C. Bioaerosol

671 analysis based on a label-free microarray readout method using surface-enhanced

672 Raman scattering. Anal. Bioanal. Chem. 2013, 405 (16), 5387-5392.

673 19. Shen, F.; Wang, J.; Xu, Z.; Wu, Y.; Chen, Q.; Li, X.; Jie, X.; Li, L.; Yao, M.; Guo,

674 X.; Zhu, T. Rapid flu diagnosis using silicon nanowire sensor. Nano Lett. 2012, 12 (7),

$675 \quad 3722-3730$.

676 20. Jin, L.; Xie, J.; Wong, C. K. C.; Chan, S. K.; Abbaszade, G.; Schnelle-Kreis, J.;

677 Zimmermann R.; Li, J.; Zhang, G.; Fu, P.; Li, X. Contributions of city-specific fine 678 particulate matter $\left(\mathrm{PM}_{2.5}\right)$ to differential in vitro oxidative stress and toxicity 
679 implications between Beijing and Guangzhou of China. Environ. Sci. Technol. 2019, $68053(5), 2881-2891$.

681 21. Li, J.; Chen, H.; Li, X.; Wang, M.; Zhang, X.; Cao, J.; Shen, F.; Wu, Y.; Xu, S.;

682 Fan, H.; Da, G.; Huang R.; Wang, J.; Chan, C. K.; Jesus, A. L. D.; Morawska, L.; Yao,

683 M. Differing toxicity of ambient particulate matter (PM) in global cities. Atmos.

684 Environ. 2019, 212, 305-315.

685 22. Pleil, J. D. Breath biomarkers in toxicology. Arch. Toxicol. 2016, 90 (11), $686 \quad 2669-2682$.

687 23. Council, N. R. Sensor systems for biological agent attacks: protecting buildings 688 and military bases; 030909576X; National Academies Press: 2005.

689 24. Kida, H.; Fukutani, Y.; Mainland, J. D.; Claire, A.; Vihani, A.; Li, Y. R.; Chi, Q.;

690 Toyama, A.; Liu, L.; Kameda, M.; Yohda, M.; Matsunami, H. Vapor detection and 691 discrimination with a panel of odorant receptors. Nat Commun 2018, 9 (1), 4556.

692 25. Rider, T. H.; Petrovick, M. S.; Nargi, F. E.; Harper, J. D.; Schwoebel, E. D.; 693 Mathews, R. H.; Blanchard, D. J.; Bortolin, L. T.; Young, A. M.; Chen, J.; Hollis, M. 694 A. A B cell-based sensor for rapid identification of pathogens. Science 2003, 301 695 (5630), 213.

696 26. Engel, Y.; Elnathan, R.; Pevzner, A.; Davidi, G.; Flaxer, E.; Patolsky, F. 697 Supersensitive detection of explosives by silicon nanowire arrays. Angew. Chem. Int. 698 Ed. 2010, 49 (38), 6830-6835.

699 27. Chen, H.; Li, J.; Zhang, X.; Li, X.; Yao, M.; Zheng, G. Automated in vivo 700 nanosensing of breath-borne protein biomarkers. Nano Lett. 2018, 18 (8), 4716-4726.

701 28. Vereb, H.; Dietrich, A. M.; Alfeeli, B.; Agah, M. The possibilities will take your 702 breath away: breath analysis for assessing environmental exposure. Environ. Sci. 703 Technol. 2011, 45 (19), 8167-8175. 
704 29. Haick, H.; Broza, Y. Y.; Mochalski, P.; Ruzsanyi, V.; Amann, A. Assessment,

705 origin, and implementation of breath volatile cancer markers. Chem. Soc. Rev. 2014, $70643(5), 1423-1449$.

707 30. Li, X.; Sinues, P. M. L.; Dallmann, R.; Bregy, L.; Hollmén, M.; Proulx, S.; Brown, 708 A. S.; Detmar, M.; Kohler, M.; Zenobi, R. Drug pharmacokinetics determined by 709 real-time analysis of mouse breath. Angew. Chem. Int. Edit. 2015, 54 (27), 7815-7818. 710 31. Broza, Y. Y.; Mochalski, P.; Ruzsanyi, V. Amann, A.; Haick, H. Hybrid 711 volatolomics and disease detection. Angew. Chem. Int. Edit. 2015, 54 (38), $712 \quad 11036-11048$.

713 32. Wang, F.; Swager, T. M. Diverse chemiresistors based upon covalently modified 714 multiwalled carbon nanotubes. J. Am. Chem. Soc. 2011, 133 (29), 11181-11193.

715 33. Aghdassi, E.; Allard, J. P. Breath alkanes as a marker of oxidative stress in 716 different clinical conditions. Free Radic. Biol. Med. 2000, 28 (6), 880-886.

717 34. Righettoni, M.; Tricoli, A.; Pratsinis, S. E. Si:WO3 sensors for highly selective 718 detection of acetone for easy diagnosis of diabetes by breath analysis. Anal. Chem. 719 2010, $82(9), 3581-3587$.

720 35. Peng, G.; Tisch, U.; Adams, O.; Hakim, M.; Shehada, N.; Broza, Y. Y.; Billan, 721 S.; Abdah-Bortnyak, R.; Kuten, A. Haick, H. Diagnosing lung cancer in exhaled 722 breath using gold nanoparticles. Nat Nanotechnol 2009, 4 (10), 669.

723 36. Fens, N.; Zwinderman, A. H.; Schee, M. P. v. d.; Nijs, S. B. d,; Dijkers, E.; 724 Roldaan, A. C.; Cheung, D.; Bel, E. H.; Sterk, P. J. Exhaled breath profiling enables 725 discrimination of chronic obstructive pulmonary disease and asthma. Am. J. Respir. 726 Crit. Care Med. 2009, 180 (11), 1076-1082.

727 37. Ahmed, W. M.; Lawal, O.; Nijsen, T. M.; Goodacre, R.; Fowler, S. J. Exhaled 728 volatile organic compounds of infection: a systematic review. ACS Infect Dis 2017, 3 
729

730

731

732

733

734

735

736

737

738

739

740

741

742

743

744

745

746

747

748

749

750

751

752

753

(10), 695-710.

38. Zhang, X.; Kang, J.; Chen, H.; Yao, M.; Wang, J. $\mathrm{PM}_{2.5}$ meets blood: in vivo damages and immune defense. Aerosol Air Qual Res 2018, 18, 456-470.

39. Wei, K.; Li, W.; Gao, S.; Ji, B.; Zang, Y.; Su, B.; Wang, K.; Yao, M.; Zhang, J.;

Wang, J. Inactivation of ricin toxin by nanosecond pulsed electric fields including evidences from cell and animal toxicity. Sci. Rep. 2016, 6, 18781.

40. Buszewski, B.; Ligor, T.; Jezierski, T.; Wenda-Piesik, A.; Walczak, M.; Rudnicka, J. Identification of volatile lung cancer markers by gas chromatography-mass spectrometry: comparison with discrimination by canines. Anal. Bioanal. Chem. 2012, 404 (1), 141-146.

41. Amal, H.; Leja, M.; Funka, K.; Lasina, I.; Skapars, R.; Sivins, A.; Ancans, G.; Kikuste, I.; Vanags, A.; Tolmanis, I.; Kirsners, A.; Kupcinskas, L.; Haick, H. Breath testing as potential colorectal cancer screening tool. Int. J. Cancer 2016, 138 (1), 229-236.

42. Mochalski, P.; Theurl, M.; Sponring, A.; Unterkofler, K.; Kirchmair, R.; Amann, A. Analysis of volatile organic compounds liberated and metabolised by human umbilical vein endothelial cells (HUVEC) in vitro. Cell Biochem. Biophys. 2015, 71 (1), 323-329.

43. Machesky, N. J.; Rusnak, J. M.; Moore, E. H.; Dorsey, C. B.; Ward, L. A. Development of a highly sensitive in vitro endothelial cell toxicity assay for evaluating ricin toxin A chain-based vaccines or therapeutics. Toxicon 2019, 167, $152-161$

44. Fernández del Río, R.; O'Hara, M. E.; Holt, A.; Pemberton, P.; Shah, T.; Whitehouse, T.; Mayhew, C. A. Volatile biomarkers in breath associated with liver cirrhosis - comparisons of pre- and post-liver transplant breath samples. 
$754 \quad$ EBioMedicine 2015, 2 (9), 1243-1250.

755 45. Daniel, D. A. P.; Thangavel, K. Breathomics for gastric cancer classification

756 using back-propagation neural network. J Med Signals Sens 2016, 6 (3), 172-182.

757 46. DeMartino, A. W.; Zigler, D. F.; Fukuto, J. M.; Ford, P. C. Carbon disulfide. Just

758 toxic or also bioregulatory and/or therapeutic? Chem. Soc. Rev. 2017, 46 (1), 21-39.

759 47. Cao, W.; Duan, Y. Breath Analysis: Potential for clinical diagnosis and exposure 760 assessment. Clin. Chem. 2006, 52 (5), 800-811.

761 48. Miekisch, W.; Schubert, J. K.; Noeldge-Schomburg, G. F. E. Diagnostic potential

762 of breath analysis - focus on volatile organic compounds. Clin. Chim. Acta 2004, 347

763 (1), 25-39.

764 49. Wang, X.; Quinn, P. J. Endotoxins: structure, function and recognition. Springer

765 Science \& Business Media: 2010; Vol. 53.

766 50. Traxler, S.; Bischoff, A.-C.; Saß, R.; Trefz, P.; Gierschner, P.; Brock, B.;

767 Schwaiger, T.; Karte, C.; Blohm, U.; Schröder, C.; Miekisch, W.; Schubert, J. K. VOC

768 breath profile in spontaneously breathing awake swine during Influenza A infection.

769 Sci. Rep. 2018, 8 (1), 14857-14857.

770 51. Lodovici, M.; Bigagli, E. Oxidative stress and air pollution exposure. J. Toxicol.

$771 \quad 2011,2011,487074-487074$.

772 52. Nichols, B. G.; Woods, J. S.; Luchtel, D. L.; Corral, J.; Koenig, J. Q. Effects of 773 ozone exposure on nuclear factor- $\kappa \mathrm{B}$ activation and tumor necrosis factor- $\alpha$ 774 expression in human nasal epithelial cells. Toxicol. Sci. 2001, 60 (2), 356-362.

775 53. Vrijens, K.; Bollati, V.; Nawrot Tim, S. MicroRNAs as potential signatures of 776 environmental exposure or effect: a systematic review. Environ. Health Perspect. $777 \quad 2015,123(5), 399-411$.

778 54. Wei, J.; Li, F.; Yang, J.; Liu, X.; Cho, W. C. MicroRNAs as regulators of airborne 
779 pollution-induced lung inflammation and carcinogenesis. Arch. Toxicol. 2015, 89 (5), $780 \quad 677-685$.

781 55. Deshpande, D.; Dileepan, M.; Walseth, T.; Subramanian, S.; Kannan, M. S.

782 MicroRNA regulation of airway inflammation and airway smooth muscle function:

783 relevance to asthma. Drug Dev. Res. 2015, 76 (6), 286-295.

784 56. Kong, A. P. S.; Xiao, K.; Choi, K. C.; Wang, G.; Chan, M. H.; Ho, C. S.; Chan, I.;

785 Wong, C. K.; Chan, J. C.N.; Szeto, C. C. Associations between microRNA (miR-21,

786 126, 155 and 221), albuminuria and heavy metals in Hong Kong Chinese adolescents.

787 Clin. Chim. Acta 2012, 413 (13), 1053-1057.

788 57. Huang, X.; Le, Q.-T.; Giaccia, A. J. MiR-210 - micromanager of the hypoxia 789 pathway. Trends Mol. Med. 2010, 16 (5), 230-237.

790 58. Aranda, J. F.; Madrigal-Matute, J.; Rotllan, N.; Fernández-Hernando, C. 791 MicroRNA modulation of lipid metabolism and oxidative stress in cardiometabolic 792 diseases. Free Radic. Biol. Med. 2013, 64, 31-39.

793 59. Hakim, M.; Broza, Y. Y.; Barash, O.; Peled, N.; Phillips, M.; Amann, A.; Haick, H.

794 Volatileorganic compounds of lung cancer and possible biochemical pathways. Chem. 795 Rev. 2012, $112(11)$, 5949-5966.

796 60. Filipiak, W., Mochalski, P., Filipiak, A.; Ager, C.; Cumeras, R.; Davis, E. C.; 797 Agapiou, A.; Unterkofler, K.; Troppmair, J. A compendium of volatile organic 798 compounds (VOCs) released by human cell lines. Curr. Med. Chem. 2016, 23(20), $799 \quad 2112-2131$.

800 61. Lord, M. J.; Jolliffe, N. A.; Marsden, C. J.; Pateman, C. S.C.; Smith, D. C.; 801 Spooner, R. A.; Watson, P. D.; Roberts, L. M. Ricin: mechanisms of cytotoxicity. 802 Toxicol. Rev. 2003, 22 (1), 53-64.

803 62. Hybertson, B. M.; Gao, B.; Bose, S. K.; McCord, J. M. Oxidative stress in health 
804 and disease: the therapeutic potential of Nrf2 activation. Mol. Aspects Med. 2011, 32

805 (4), 234-246.

806 63. Maritim, A. C.; Sanders, R. A.; Watkins Iii, J. B. Diabetes, oxidative stress, and

807 antioxidants: A review. J. Biochem. Mol. Toxicol. 2003, 17 (1), 24-38.

808 64. Birben, E.; Sahiner, U. M.; Sackesen, C.; Erzurum, S.; Kalayci, O. Oxidative 809 stress and antioxidant defense. World Allergy Organ J 2012, 5 (1), 9-19.

810 65. Kosmider, B.; Loader, J. E.; Murphy, R. C.; Mason, R. J. Apoptosis induced by 811 ozone and oxysterols in human alveolar epithelial cells. Free Radic. Biol. Med. 2010, $81248(11), 1513-1524$.

813 66. Filipiak, W.; Ruzsanyi, V.; Mochalski, P.; Filipiak, A.; Bajtarevic, A.; Ager, C.;

814 Denz, H.; Hilbe, W.; Jamnig, H.; Hackl, M.; Dzien, A. Dependence of exhaled breath 815 composition on exogenous factors, smoking habits and exposure to air pollutants. $J$. $816 \quad$ Breath Res. 2012, 6 (3), 21.

817 67. Amann, A.; Costello, B. d. L.; Miekisch, W.; Schubert, J.; Buszewski, B.; Pleil, J.; 818 Ratcliffe, N.; Risby, T. The human volatilome: volatile organic compounds (VOCs) in 819 exhaled breath, skin emanations, urine, feces and saliva. J. Breath Res. 2014, 8 (3), $820 \quad 034001$.

821 68. Vander Heiden, M. G.; Cantley, L. C.; Thompson, C. B. Understanding the 822 Warburg effect: the metabolic requirements of cell proliferation. Science (New York, $823 \quad$ N.Y.) 2009, 324 (5930), 1029-1033.

824 69. Hochachka, P. W. Defense strategies against hypoxia and hypothermia. Science 825 1986, 231 (4735), 234.

826 70. Laffel, L. Ketone bodies: a review of physiology, pathophysiology and 827 application of monitoring to diabetes. Diabetes Metab. Res. Rev. 1999, 15 (6), $828 \quad 412-426$. 
829 71. Wlodzimirow, K.A., Abu-Hanna, A.; Schultz, M. J.; Maas, M. A. W.; Bos, L. D. J.;

830 Sterk, P. J.; Knobele, H.H.; Soers, R.J.T.; Chamuleau, R. A. F. M., Exhaled breath

831 analysis with electronic nose technology for detection of acute liver failure in rats.

832 Biosens. Bioelectron. 2013, 53, 129-134.

833 72. Simone M., Kyu-Bok J., Barbara B.; Blake, D. R.; Vaziri, N. D., Exhaled breath

834 and fecal volatile organic biomarkers of chronic kidney disease. Biochim. Biophys.

835 Acta, Gen. Subj. 2013, 1830(3), 2531-2537.

836 73. Mochalski P.; Al-Zoairy R.; Niederwanger A.; Unterkofler K.; Amann A.,

837 Quantitative analysis of volatile organic compounds released and consumed by rat L6

838 skeletal muscle cells in vitro. J. Breath Res. 2014, 8(4), 046003. 